\title{
DA IMPREVISIBILIDADE À ESPERANÇA: DIÁLOGOS COM BOAVENTURA E FREIRE EM TEMPOS PANDÊMICOS
}

DOI: $10.48075 / R I . V 24 I 2.26519$

\begin{abstract}
Egeslaine de $\mathrm{Nez}^{1}$
Richéle Timm dos Passos da Silva² Odorico Ferreira Cardoso Neto ${ }^{3}$

RESUMO: No ano de comemoração do centenário de Paulo Freire, esse artigo pretende aprofundar algumas reflexões do seu legado e a possibilidade de uma atitude comunicativa com os escritos de Boaventura Sousa Santos. O diálogo proposto entre esses autores indica que a reflexão é um processo de conquista, de construção, de criação, que depende da consciência de todos e requer para tanto a abertura a outras racionalidades. Algumas das interpelações deste ensaio teórico sinalizam a potencialização dos sujeitos, com vistas a emancipação social, a partir da pedagogia do conflito, do diálogo e da problematização, perpassando, dessa forma, nosso objetivo textual. Inquieta pensar como as ideias desses autores auxiliam na construção da cidadania, a fim de contribuir com a construção de uma sociedade mais justa e igualitária. A relevância deste texto assenta-se na contribuição ao campo educacional que almeja ser uma forma de intervenção no mundo consciente e dialógico. Finalmente, insistimos na importância do aspecto comunicativo dialógico, crítico e participativo que permeia todo o texto, pois, essa é a solicitação urgente a todos que almejam, esperançosos, por uma sociedade aberta às pluralidades numa convivialidade hospitaleira.
\end{abstract}

Palavras-chave: Diálogo; Freire; Boaventura; pedagogia da esperança; pedagogia do vírus.

\section{FROM UNPREDICSIBILITY TO HOPE: DIALOGUES WITH GOOD ADVENTURE AND FREIRE IN PANDEMIC TIMES}

ABSTRACT: In the year of Paulo Freire's centenary commemoration, this article intends to deepen some reflections on his legacy and the possibility of a communicative attitude with the writings of Boaventura Sousa Santos. The dialogue proposed between these authors indicates that reflection is a process of conquest, construction, creation, which depends on everyone's conscience and requires, for that, an opening to other rationalities. Some of the challenges of this theoretical essay signal the empowerment of subjects, with a view to social emancipation, from the pedagogy of conflict, dialogue and problematization, thus passing through our textual objective. It is restless to think

\footnotetext{
${ }^{1}$ Doutora em Educação. Departamento de Estudos Especializados (DEE), Faculdade de Educação (FACED) da Universidade Federal do Rio Grande do Sul (UFRGS).E-mail: e.denez@yahoo.com.br.

${ }^{2}$ Mestre em Educação. Departamento de Fundamentos da Educação, Faculdade de Educação da Universidade Federal de Pelotas (UFPel). E-mail: richelertps@gmail.com

3 Doutor em Educação. Instituto de Ciências Humanas e Sociais (ICHS) da Universidade Federal de Mato Grosso (UFMT), Campus Universitário do Araguaia (CUA). E-mail: kikoptbg@gmail.com
} 
about how the ideas of these authors help in the construction of citizenship, in order to contribute to the construction of a fairer and more egalitarian society. The relevance of this text is based on its contribution to the educational field that aims to be a form of intervention in the conscious and dialogic world. Finally, we insist on the importance of the dialogical, critical and participative communicative aspect that permeates the entire text, as this is the urgent request to all who hopefully long for a society open to pluralities in a hospitable conviviality.

Key Words: Dialogue; Freire; Boaventura; pedagogy of hope; pedagogy of the virus.

\section{INTRODUÇÃO}

Em tempos de desestabilização proveniente de uma situação provocada por um vírus letal (sars-cov-2) ${ }^{4}$, algumas esperanças oriundas da pedagogia freireana nos acalentam diante de tantos desafios e provocações postos para a educação. A humanização, a sensibilidade, o cuidado com o outro, o diálogo, a escuta e tantos outros elementos teóricocríticos da pedagogia freireiana, nos impulsionam a reafirmar a educação humanizadora, transformadora e emancipatória na pós-pademia.

Diante dos dilemas educacionais impostos por uma epistemologia de racionalidade dominante, por uma ciência pura e utilitarista, se faz necessária uma vigilância epistemológica crítico-reflexiva para que não nos deixemos sufocar por esses pressupostos esmagadores de uma realidade niilista ${ }^{5}$.

Neste contexto, inquieta-nos pensar como as ideias de Paulo Freire ${ }^{6}$ podem responder as elucubrações de Boaventura de Sousa Santos $^{7}$ sobre a pedagogia do vírus

\footnotetext{
${ }^{4}$ A COVID-19 é uma doença infecciosa causada por um coronavírus recém-descoberto. A Organização Mundial da Saúde (OMS) declarou, em janeiro de 2020, que o surto da doença constitui uma emergência de saúde pública de importância internacional. Em março, foi caracterizada como uma pandemia. Foram confirmados no mundo 29.737.453 casos e 937.391 mortes até o dia 19 de setembro (data que celebra os 99 anos de Freire) (OPAS, 2020).

${ }^{5}$ O niilismo é uma corrente filosófica que acredita no vazio. O conceito está pautado na subjetividade do ser. Do latim, o termo "nihil" significa "nada". Trata-se, portanto, de uma filosofia, que apoiada ao ceticismo, é destituída de normas indo contra os ideais das escolas materialistas e positivas (DELEUZE, 2001).

${ }^{6}$ Educador e filósofo da educação humanizadora. Considerado um dos pensadores mais notáveis na história da pedagogia mundial, tendo influenciado o movimento chamado pedagogia crítica. É também o Patrono da Educação Brasileira. Suas obras são reconhecidas mundialmente, traduzidas para vários idiomas. Seus escritos versam sobre a relação dialógica problematizadora e uma teoria epistemológica sobre a ação dialógica (BRANDÃO, 1981).

${ }^{7}$ Sociólogo e professor catedrático da Faculdade de Economia da Universidade de Coimbra. Seus trabalhos foram traduzidos para o espanhol, inglês, italiano, francês e alemão. Dos seus conceitos fundamentais, destacam-se a sociologia das ausências e das emergências, a ecologia de saberes, a linha abissal, o pensamento pós-abissal, o epistemicídio, a interlegalidade, o Estado heterogêneo, a razão indolente, a razão metonímica e o fascismo social. A abordagem de seus estudos está voltada à possibilidade de reinvenção da teórica crítica (Disponível em: http://www.boaventuradesousasantos.pt/pages/pt/cv-e-nota-biografica.php. Acesso em: 18 set. 2020).
} 
instaurada a partir da disseminação e do contágio em escalas planetárias dessa doença. Assim, pretende-se aprofundar algumas reflexões do legado de Paulo Freire e a possibilidade de uma conversa com os escritos de Boaventura.

O diálogo proposto entre esses autores sugere que a reflexão é um diálogo transformador, um processo de conquista, de construção, de criação, o qual depende da participação ativa dos indivíduos na sociedade. O ser humano, como um ser de convivência, um ser de relação, com outros humanos e ainda com os não-humanos, é esse "homoconvivalis" que em período pandêmico tem experienciado formas tão estranhas de conviver. Espera-se que dos diálogos transformadores provenientes também dessa experiência, brote uma convivialidade capaz de acolher ao outro, entendê-lo e respeitá-lo, portanto, hospitaleira. (OLMEDO, 2006).

É esse, portanto, o momento propício para o exercício reflexivo do pensar. Nez (2014, p.15) caracteriza que toda reflexão é uma atividade voltada para a solução de problemas, é uma busca, indagação e investigação da realidade. "É uma atividade que permite elaborar um conhecimento, ou um conjunto deles, que auxilie na compreensão da realidade e possa orientar ações para a transformação".

Vale destacar que a problematização desse ensaio teórico é compreendida como nos indica Freire (1987), sendo possível apenas na sua dimensão concreta, presente e histórica. Então, resgatar o passado (pedagogia da esperança) é analisá-lo criticamente, em relação dialógica com a situação presente (pedagogia do vírus), permitindo que se revele ao futuro, a possibilidade e o desejo de ser mais.

Ainda, segundo Freire (1996) essa ação reflexiva confere sentido às situações problematizadas, abrindo possibilidades para o seu controle intencional e deliberado, introduzindo o eu como agente e fonte de pensamento. Essa proposição dialógica se reflete num indivíduo dialógico em movimento de diálogo com os outros seres a partir da vivência em um mundo compartilhado.

Esse movimento caracteriza um diálogo inteligente com a realidade, tomando-o como processo e atitude, e, como integrante do cotidiano. É nesse espaço que se instaura o diálogo como estratégia de descoberta, de guia e de proposição, elemento central para o estabelecimento de uma convivência acolhedora, hospitaleira, ante a pluralidade dos indivíduos e de suas culturas.. Trata-se, pois, de buscar desvelar algumas das diversas 
dimensões que compõem as problemáticas cotidianas, para condução à reflexão coletiva, fundamentalmente necessária nesse período da pandemia.

Para isso, esse estudo está dividido em três partes, além das considerações iniciais e finais. Na primeira, o foco é em Freire e a pedagogia da esperança; na segunda parte, se apresenta a pedagogia do vírus de Boaventura; e, na terceira parte, um reencontro equilibrado entre os dois, em busca do diálogo com a realidade tendo como horizonte a convivência hospitaleira entre asas diferentes vozes na sua pluralidade.

\section{PAULO FREIRE E A PEDAGOGIA DA ESPERANÇA}

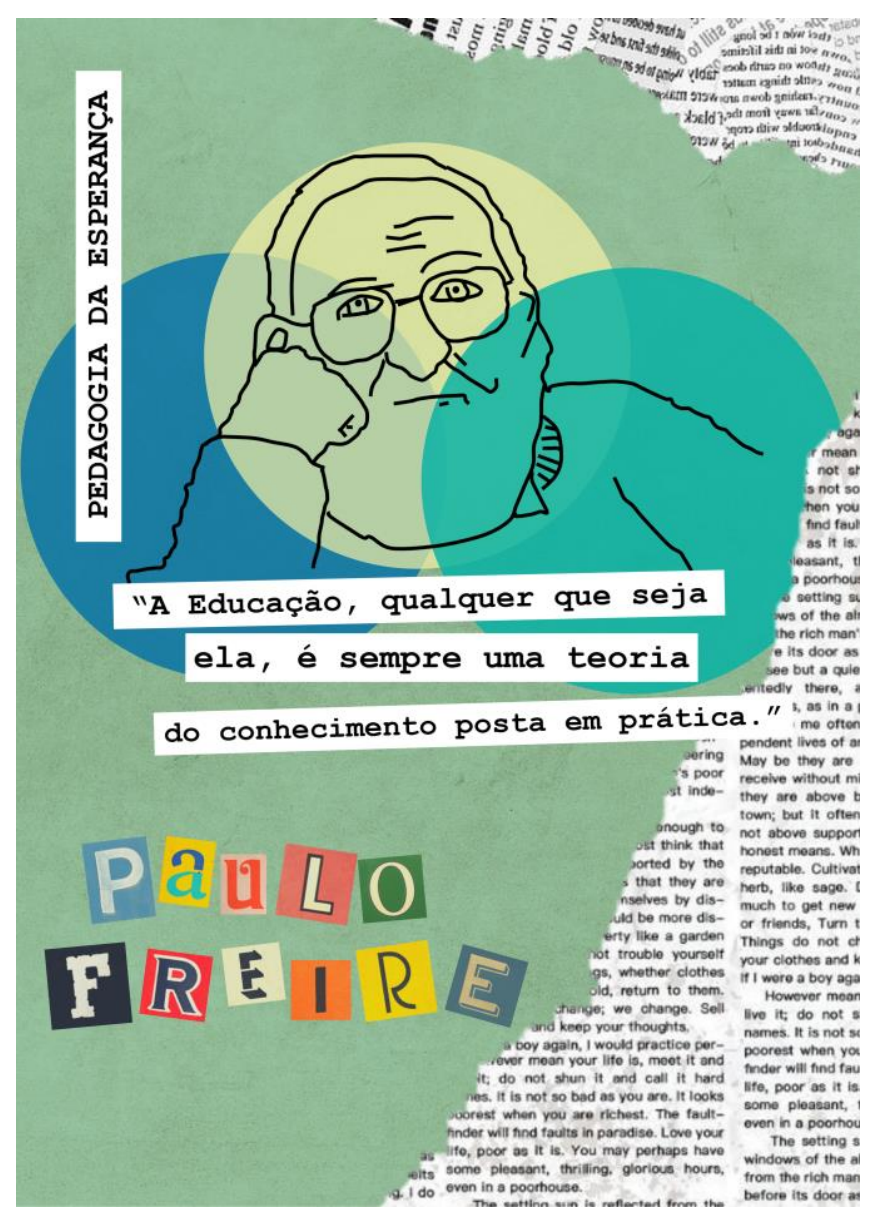

Fonte: Os autores (2020).

Arte: Marina Santos Graziano de Oliveira (2020).

A situação presente pregou uma peça aos desavisados, aos cristãos, ateus, agnósticos, aos que dizem não serem nada. A pedagogia do vírus vinha há muito tempo mostrando suas garras poderosas, pois mais de cinquenta anos depois a epígrafe de Freire registrada na sua obra-prima já indicava: "aos esfarrapados do mundo e aos que neles se descobrem e, assim descobrindo-se com eles sofrem, mas, sobretudo, com eles lutam" 
(FREIRE, 1987, p. 25). É fundamental não perder de vista as relações e as aproximações que se estabelecem no esteio da dor e da esperança. Assim, somos os esfarrapados no mundo de hoje quando nos distanciamos do diálogo amoroso e acolhedor em momento tão ímpar que estamos vivendo.

Não é, por acaso, querer estabelecer dialeticamente um diálogo crítico (pedagogia da esperança) com a situação presente (pedagogia do vírus), permitindo começar um embate para fazer da esperança uma prática na concretude histórica. Para voltar ao passado, objetivando significar e ressignificar o presente, antevendo o futuro, Freire já anunciava em 1959,

Cada vez mais nos convencíamos ontem e nos convencemos hoje, de que o homem brasileiro tem de ganhar a consciência de sua responsabilidade social e política, existindo essa responsabilidade. Vivendo essa responsabilidade. Participando. Atuando. Ganhando cada vez maior ingerência nos destinos da escola de seu filho. Nos destinos de seu sindicato. De sua empresa, através de agremiações, de clubes, de conselhos. Ganhar ingerência na vida de seu bairro. Na vida de sua comunidade rural, pela participação atuante em associações, em clubes, em sociedades beneficentes. Assim, não há dúvida, iria o homem brasileiro aprendendo democracia mais rapidamente (1959, p. 13).

Por isso, soa profético o anúncio de Freire de que "não há esperança na pura espera, nem tão pouco se alcança o que espera na espera pura, que vira, assim espera vã" (FREIRE, 1987, p. 10-11). Vive-se cercado por um "latifúndio de dúvidas, incertezas, inconclusões, perplexidades" potencializadas pela pandemia, ao mesmo tempo, grávidos de esperança de que a educação é um dos meios que os homens lançam mão para satisfazerem suas necessidades. É fundamental considerar que isso pode ocorrer onde não há escola e por toda parte pode haver redes e estrutura sociais de transferência de saber de uma geração a outra ${ }^{8}$.

A evolução da cultura humana levou o homem a construir o a transmitir conhecimento, criando situações sociais de ensinar-aprender-ensinar. Educação e escola se completam como necessidade política do homem, por isso, "não sou esperançoso por pura

\footnotetext{
${ }^{8}$ Há aqui, uma aproximação do pensamento freireano com o conceito de ecologia de saberes de Boaventura: "Trata-se do conjunto de intervenções epistemológicas que denunciam a supressão dos saberes levada a cabo, ao longo dos últimos séculos, pela norma epistemológica dominante, valorizam os saberes que resistiram com êxito e as reflexões que estes têm produzido e investigam as condições de um diálogo horizontal entre conhecimentos. A esse diálogo entre saberes chamamos ecologias de saberes" (SANTOS e MENESES, 2010, p. 7). 
teimosia, mas por imperativo existencial e histórico" (FREIRE, 1992, p. 10), a esperança é uma invenção humana, histórica e social e que, sem ela, não há mudanças. Ter esperança é possuir um projeto e não apenas um sonho ingênuo; visto que esperança e sonho fazem parte da humanidade, e é, por isso, que os ditadores tentam oprimir e acabar com a esperança, pois quando não há sonho, fica-se estagnado

É preciso ter esperança, mas esperança do verbo esperançar; porque tem gente que tem esperança do verbo esperar. E esperança do verbo esperar não é esperança, é espera. Esperançar é se levantar, esperançar é ir atrás, esperançar é construir, esperançar é não desistir! Esperançar é levar adiante, esperançar é juntar-se com outros para fazer de outro modo (FREIRE, 2001a, p. 110-111).

A esperança engajada coloca educadores e educadoras com responsabilidade de compreender o processo histórico de transformação social como contínuo, imensurável, não sustentado por projetos individuais, mas sim por atitudes e ações coletivas, permeadas no continuum diálogo. As atitudes elevam o espírito humano à condição de excelência ética a favor de um projeto socialmente qualitativo de educação sustentável.

Outros desafios se apresentam cada dia no pensar da sociedade, da educação e da escola, pois que cada vez mais o sentimento de responsabilidade pelos destinos de nós mesmos e quiçá do "outro mundo possível" exigem novas posturas. Outro contrato social, diferentemente do que está posto, desafia enfrentar a barbárie da falta de compromisso e atitude frente aos novos desafios que questionam a própria forma de questionar a realidade.

Freire e o projeto de esperança engajada se produz nas inquietudes intelectuais, educacionais e profundamente humanas que colocam educadores e educadoras frente a frente com desafios perquiridores. A perquirição aponta para a necessidade de pontes a ligar a educação brasileira aos pressupostos sócios-geopolíticos-econômicos-culturaiseducacionais ainda cheios de incompletudes a serem exploradas. O Brasil é país em construção, em busca de rumo, que precisa de educadores formulando, fazendo, agindo, construindo e oportunizando outros saberes na perspectiva da educação formal e informal.

As reflexões que podem garantir o fazer e o pensar pedagógico interpretam que as políticas públicas para a educação devem ser terreno cultural da contestação e não podem ser espaço da palavra esvaziada, de intelectuais descompromissados com o homem do campo, da cidade, da fábrica, do subúrbio, da favela ou do bairro. A educação é espaço de 
atividades culturais fundidas, buriladas na proeminência do diálogo, da interrogação crítica da vivência, no desvelamento das contradições sociais e na promulgação de relações sociais democráticas.

No dizer strictu sensu de Freire (1996, p. 108), “a educação não vira política por causa da decisão deste ou daquele educador. Ela é política [...]". Também se pode afirmar que:

[...] na verdade toda vez que o futuro seja considerado como um pré-dado, ora porque seja a pura repetição mecânica do presente [...] ora porque seja o que teria de ser, não há lugar para a utopia, portanto para o sonho, para a opção, para a decisão, para a espera na luta... Não há lugar para a educação. Só para o adestramento (FREIRE, 1992, p. 92).

Os ensinamentos de Freire ajudam, problematizam, evidenciam e humanizam a realidade, assinalando uma educação que seja dialógica em um ambiente democrático, elementos essenciais para a construção de uma educação transformadora. Do ponto de vista governamental, entre avanços e regressos, a democracia e a esperança estão em xeque, a gestão democrática das escolas também está a perigo. Conforme entendimento do Supremo Tribunal Federal (STF), os diretores das escolas públicas deverão ser nomeados pelos prefeitos, no caso da rede municipal, e pelo governador, quando se tratar de escolas estaduais 9 .

Dentro de um contexto de perplexidade e de obviedades, reafirma-se que a educação é um dos principais meios de realização da mudança e da transformação social. Ao mesmo tempo provoca desigualdade, tendo em vista a contraposição da práxis da escola plural, cidadã, de luta, humanitária, emancipatória e a escola tradicional. Pontos de vista esses que pode ser lido diante de um viés formativo predominantemente oriundo de uma epistemologia hegemônica, dominadora, de premissas excludentes e hierárquicas na dinâmica do saber, características marcantes no constructo da escola moderna.

O exercício humanizador da educação escolar pensa que o processo educacional nunca está pronto e acabado, é essencialmente dialético e dialógico, pode ser reinventado, transcende a aventura humana. A educação transformada em esperança, se fundamenta em acreditar que o ato humano de educar existe tanto no trabalho pedagógico, quanto no ato

\footnotetext{
${ }^{9}$ Entendimento construído a partir das conexões estabelecidas entre http://www.stf.jus.br/portal/cms/verNoticiaDetalhe.asp?idConteudo=\%20111821, https://cmoreira2.jusbrasil.c om.br/artigos/769117370/eleicao-para-diretor-escolar e https://muvucapopular.com.br/politica/sintepafirma-que-mendes-mente-sobre-proibicao-do-stf-em-relacao-a-eleicoes-nas-escolas/41748. Acesso em: 10 nov. 2020.
} 
político, que se trava por outro tipo de escola e outro tipo de mundo. A educação pode ser ao mesmo tempo, movimento e ordem, sistema e contestação.

O estilo de vida sustentável, que combate o sistema e educa para outros mundos possíveis tem o horizonte apontado para a construção de um projeto de autonomia, amparado na compreensão de que o sentido da democracia completa a dimensão da educação e da escola como necessidade política do homem. Esse pressuposto gera um questionamento: "A que, e a quem serve a educação, a escola e a própria política"? Assim posto, há que se vislumbrar o caráter político do homem expondo sua criação e sua relevância no que se refere à imaginação criadora, a reinvenção social da educação e da escola, fortalecendo a noção de sujeito de direitos.

O referencial teórico da prática de muitos educadores (as) Brasil afora tem muita similitude com a pedagogia do oprimido ao fazer o enfrentamento do dualismo educacional. Também com a pedagogia da autonomia, quando indica que a educação não é linear, se expressa nos seus altos e baixos, é luta cotidiana contra as desigualdades, ação pensar/refletir cotidianamente sobre a contradição da educação humanizadora versus educação mercantilista.

Em sendo assim, "não basta incluir, é preciso emancipar", é preciso ser movido pela esperança, pelo sentido e poder de atuação que cumpre importante função estratégica para o desenvolvimento do país, das instituições e das pessoas.

É pela palavra, dita, não calada, que não sendo privilégio de apenas alguns homens, podemos instituir, na escola, uma construção dialógica, em vista de uma sociedade aberta as pluralidades de saberes e hospitaleira na convivência entre as diferentes gentes.

Para superar a tendência "do já feito", a proposição é antiga, mas nunca completada: democratizar o conhecimento acadêmico, promovendo a participação da sociedade, formando o cidadão para a vida e para o mundo. A proposição tem o desafio de compreender que não se deve e não se pode apenas ouvir falar de Paulo Freire, mas refletir e colocar em prática suas teorias e concepções de educação, escola e política. Por isso, essa tentativa de conversa com Boaventura em busca de um reencontro equilibrado em vista de um diálogo possível e necessário.

"A insustentável leveza do ser" busca equilíbrio numa educação que misture simplicidade e ousadia, articule um novo conceito de educação, escola, política, sala de aula, currículo e de ação integrada; e, principalmente, que invista numa abordagem impregnada pela "utopia e pela ideia de que o mundo pode ser melhor". A possiblidade de Ideação. Revista do Centro de Educação, Letras e Saúde. v. 23, n², 2021. e-ISSN: 1982-3010. 
enfrentamento segue a trilha "que centra a educação nas pessoas e não no indivíduo, não é fatalista, não nega a utopia em que mudar as pessoas são processos interligados, interdependentes e convergentes". Assim, a esperança e a utopia podem ser mensuradas com o seguinte excerto,

A exploração de novas possibilidades e vontades humanas, por via da oposição da imaginação à necessidade do que existe, só porque existe, em nome de algo radicalmente melhor que a humanidade tem direito de desejar e por que merece a pena lutar. A utopia é, assim, duplamente relativa. Por um lado, é uma chamada de atenção para o que não existe como (contra) parte integrante, mas silenciosa, do que existe. Pertence à época pelo modo como se aparta dela. Por outro lado, a utopia é sempre desigualmente utópica, na medida em que a imaginação do novo é composta em parte por novas combinações e novas escalas do que existe. Uma compreensão profunda da realidade é assim essencial ao exercício da utopia, condição para que a radicalidade da imaginação não colida com o seu realismo (SANTOS, 2008, p. 323) [grifo nosso].

\section{BOAVENTURA E A PEDAGOGIA DO VÍRUS}

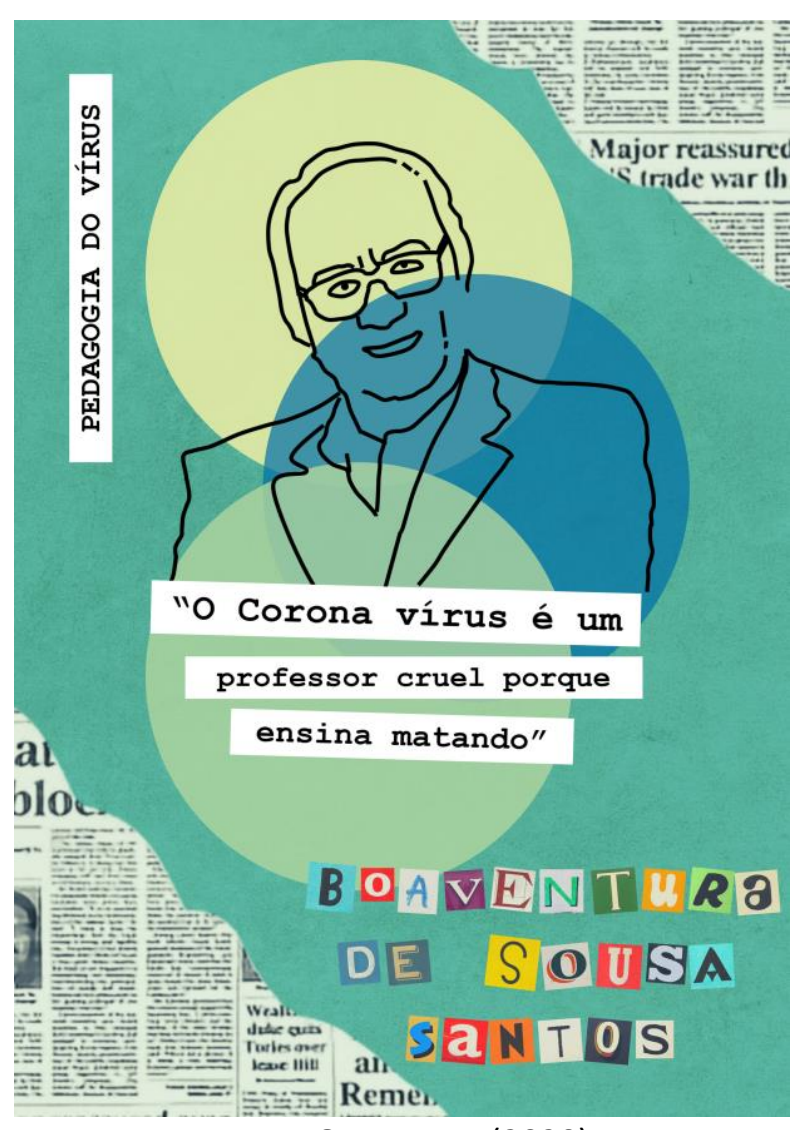

Fonte: Os autores (2020).

Arte: Marina Santos Graziano de Oliveira (2020). 
O ano de 2020 teve início com dois grandes acontecimentos: a recessão econômica mundial e a perigosa difusão planetária da Covid-19. Isso gerou tendências que estão inferindo no destino de povos e nações, que passam pelo isolamento social e por uma longa quarentena. Santos (2020, p. 15) expõe que: "qualquer quarentena é sempre discriminatória, mais difícil para uns grupos sociais do que para outros e impossível para um vasto grupo de cuidadores [...]".

O colapso dos mercados financeiros e da economia é uma ideia que assombra o planeta a todo instante e está relacionada com a evolução do coronavírus no Brasil. Embora de difícil mensuração, em virtude da subnotificação, decorrente da falta de testes e do desigual acesso à rede pública de saúde, é nítida a olhos nus.

A pandemia é uma alegoria. Para Santos (2020), o sentido literal da pandemia do coronavírus é o "medo caótico generalizado e a morte sem fronteiras causados por um inimigo invisível" (p. 10). Mas, o que exprime está muito além disso! O neoliberalismo como projeto hegemônico revelou seus limites ecológicos, energéticos, sociais, culturais e políticos antes que a pandemia viesse a expor, os limites a que nos conduziu um sistema reprodutivo de injustiça, desigualdade e violência.

O surgimento da COVID-19 gerou um cenário sem igual na história da humanidade: pela primeira vez, os sistemas de educação formal em todo o mundo cessaram sua dinâmica presencial. Muitos países implementaram o fechamento de escolas de forma localizada, isso deixou, segundo a Organização das Nações Unidas para a Educação, a Ciência e a Cultura (UNESCO), 1,37 bilhão de crianças fora dos estabelecimentos de ensino. Esses fechamentos provocaram um impacto gigantesco em mais de $70 \%$ da população estudantil mundial.

Com a ausência de vacinas e um tratamento complexo que precisa de respiratórios artificiais os quais são poucos na rede de saúde brasileira, os clamores das instituições científicas de pesquisa e da Organização Mundial da Saúde (OMS) foram ouvidos de alguma forma: "não há outro jeito de impedir uma imensa catástrofe humanitária de alcance mundial do que as políticas de confinamento social" (COLEMARX, 2020, p. 6). Assim, alguns setores produtivos foram forçados a interromper seus processos de produção, fronteiras e comércios fechados, atividades culturais e educacionais suspensas por tempo indeterminado.

Diante dessa situação, a resposta do governo brasileiro às novas condições impostas pela pandemia foi garantir a continuidade das atividades por meio das tecnologias 
(ensino remoto emergencial ${ }^{10}$ ). No México, Chile, Uruguai e muitos outros países, houve iniciativas de usos de tecnologias digitais na educação em todos os níveis. Essas envolvem aplicativos gratuitos, programas de televisão, plataformas de aprendizagem, entre outras possibilidades. No Brasil, as iniciativas são tímidas, e, no momento gradativamente, substituídas pelo ensino híbrido ${ }^{11}$ em alguns estados.

Segundo Santos (2020), o cenário do trabalho docente se intensificou. As desigualdades aumentaram enquanto outras foram geradas. A falta de conectividade, dispositivos tecnológicos e espaços adequados afetam os alunos e os professores. O espaço público invadiu o privado.

A esfera pública, entendida como estrutura comunicativa, perpassa todas as relações sociais e, portanto, poder-se-ia chamar atenção à escola, como um espaço público, das coletividades das vozes, como essa esfera pública do "espaço de trato comunicativo e racional entre as pessoas" (HABERMAS, 2007, p. 18-19).

Esse complexo institucional, num sentido comunicativo, adentrou as casas (propriedade privada) o que ocasionou uma ampliação do sentido territorial (educação escolar somente nas escolas) vivido para um sentido de comunicação entre os indivíduos e reorganizou a experiência vivida e compartilhada entre os frequentadores do espaço territorial público - escola - e os indivíduos do espaço territorial privado - família/casas.

Nesse entremeio, entre ganhos e perdas salientes a todos, acentuaram-se outras demandas decorrentes os quais se apontaram como desvios substantivos: a ampliação dos níveis de injustiça educacional e o aprofundamento das tendências mercantis e privatizantes da educação.

Nessa conjuntura foi aberto um processo inédito de trabalho coletivo caracterizado com intensas trocas. Tais dinâmicas foram complementadas com processos de construção curricular que partiram de pedagogias tradicionais (pedagogia do oprimido - educação bancária) que são voltadas para a mera transmissão de conhecimentos, para possibilitar um caminho alternativo de uma educação democrática e emancipatória. Re-forçando a necessidade de re-viver o espaço público comunicativo intrínseco a educação escolar.

\footnotetext{
$10 \mathrm{O}$ ensino remoto emergencial se caracteriza numa transmissão em tempo real das aulas (síncronas). Isso significa dizer que o docente e os acadêmicos tem a possibilidade de interagir nos horários em que as aulas da disciplina ocorreriam no modelo presencial (ARRUDA, 2020).

${ }^{11}$ É uma das maiores tendências da educação do século XXI, que busca aliar métodos de aprendizado de modo síncrono, assíncrono, além do presencial. Arruda (2020) expõe que a metodologia busca integrar a tecnologia, que já permeia significativamente alguns aspectos da vida do estudante.
} 
Algumas questões podem nos auxiliar a pensar um projeto educativo que, no nosso ponto de vista, pode corroborar com os ideais freireanos de emancipação e transformação nesse contexto; e, além disso, postular uma produção fora dos centros hegemônicos, a partir da ecologia dos saberes. Santos (2007) discute o pensamento abissal da epistemologia moderna ocidental e suas lacunas, apontando que paira um padrão de hierarquização no qual, as epistemologias também foram suprimidas com o processo de colonização do norte.

Santos () sustenta quem observa o futuro como progresso, não evidencia com tanta importância o passado, a memória, a história vivida e, portanto, acaba desvalorizando "[...] sistematicamente o passado em benefício do futuro" (1996, p.16). Na pedagogia do vírus, reforça essa ideia na argumentação sobre os desdobramentos da pandemia à luz da situação econômica e política dos últimos anos.

Contudo, o futuro que vislumbra apenas o progresso, que desconsidera o passado e a historicidade construída pela ação do sujeito, segundo Santos (1996), fez com que houvesse a morte do inconformismo e da rebeldia e, com isso, a perda da capacidade de indignação diante de atrocidades cometidas.

Um resgate a esse postulado seria trabalhar com as questões da memória e da historicidade, através de um projeto educativo orientado e comunicativo "por via da produção de imagens desestabilizadoras a partir do passado concebido não como fatalidade, mas como produto da iniciativa humana" (SANTOS, 1996, p. 17). Com isso, a indicação consistiria em recuperar a capacidade de espanto e de indignação dos sujeitos históricos e conscientes desse processo.

Nessa perspectiva, trabalhar com um projeto educativo emancipatório é partir do conflito entre os conhecimentos, inquietar e estimular o educando com práticas educativas que Ihe possibilite construir seu conhecimento. A ciência, em Santos (1996), assume a perspectiva do modelo de aplicação edificante e não de aplicação técnica (educação bancária), já que o conhecimento não se sobressai hierarquicamente e, portanto, não há uma homogeneidade de se pensar e fazer conhecimento. É a ecologia dos saberes que se aponta como possibilidade de incluir as epistemologias não reconhecidas pela educação escolar da modernidade.

A pedagogia do vírus vai nessa direção. Assim, criam-se sujeitos que entendem ciência e conhecimento a partir do conflito, alargando o sentido cultural, ético e político dos argumentos utilizáveis por todos. Desta forma, o conhecimento "serve" como emancipação Ideação. Revista do Centro de Educação, Letras e Saúde. v. 23, n², 2021. e-ISSN: 1982-3010. 
contra o conhecimento com vistas à regulação e esse processo de "fazer ciência" nos impulsiona a pensar e querer a busca de um "conhecimento prudente para uma vida decente" (SANTOS, 1996,2004).

As súbitas mudanças de hábitos impostas em todo o planeta, como o tempo dispensado aos filhos, a diminuição da poluição nas grandes cidades e a redução do consumo desenfreado provocados pela pandemia, "Mostra-se que só não há alternativas porque o sistema político democrático foi levado a deixar de discutir as alternativas" (SANTOS, 2020, p. 6).

As alternativas não discutidas revelam o empobrecimento do diálogo pelas questões sociais e políticas do espaço público. Na ausência ou no enfraquecimento de diferentes vozes, os monólogos surgem direcionados por grupos homogêneos e imperialistas na forma de relacionar-se e de viver em sociedade e isso vem determinando e impondo o ritmo à vida. A escola é chamada a ser repensada nesse ínterim e incluir a pluralidade de vozes esquecidas ou excluídas no discurso sobre o sentido de ser e existir da educação escolar na atual sociedade.

Ainda, é possível inferir que aos grupos mais afetados pela crise ao redor do mundo, o capitalismo enquanto modelo social, prova sua inabilidade: "Só com uma nova articulação entre os processos políticos e os processos civilizatórios será possível começar a pensar uma sociedade em que a humanidade assuma uma posição mais humilde no planeta que habita" (SANTOS, 2020, p. 31).

\section{O REENCONTRO EQUILIBRADO PARA A CONVIVENCIA HOSPITALEIRA}

19 de setembro é a data de nascimento de Paulo Freire e uma das principais referências da pedagogia latino-americana, que percebeu o processo educativo como um caminho de libertação cultural, social e política pautado em uma constante relação dialógica. Referência obrigatória para pensar e implantar projetos de transformação e emancipação social, as obras freireanas têm contribuído para contestar o modelo neoliberal que há décadas tenta se solidificar no nosso continente.

O diálogo inteligente com a realidade, tomando-o como processo e atitude, e, como integrante do cotidiano é o princípio basilar dessa parte do estudo. Freire (1987) considera que: “O diálogo é este encontro dos homens, mediatizados pelo mundo, para pronunciá-lo, 
não se esgotando, portanto, na relação eu-tu" (p. 78). É nesse espaço que se instaura o diálogo como sua dimensão compreensiva na epistemologia que se propõe ler, interpretar, traduzir e comunicar as diferentes vozes.

Promovendo o encontro consigo mesmo e com o outro, mediatizados pelo mundo, constructo da realidade vivida e experenciada, refletida e comunicada, as interações especialmente, as promovidas pela escola, lançam-se na esfera de humanização amorosa com fins a uma convivência hospitaleira.

Como ser de relação, o ser se faz ser enquanto em processo de relação com outros seres vivos e não vivos. Por isto, é uma exigência existencial. $E$, se é o encontro em que se solidarizam o refletir e o agir dos sujeitos endereçados ao mundo a ser transformado e humanizado, "não pode reduzir-se a um ato de depositar idéias de um sujeito no outro, nem tampouco tornar-se simples troca de idéias a serem consumidas pelos permutantes" (FREIRE, 1987, p. 79).

A convivência, ou ainda a capacidade de convivialidade, é um termo significativo para compreender a necessidade vital contida nas relações. Porém, essa capacidade de conviver, estabelecida a partir dos diálogos nas relações, não deve pautar-se na instrumentalização dos sujeitos reduzindo-os a meros objetos. Nesse ponto, acrescenta-se a compreensão de Ivan Illich (2019) que utiliza o termo convivencialidade o coloca em oposição ao que requer à produtividade industrial, imposta pela modernidade e seu modelo de desenvolvimento, ao refletir sobre a imposição e ruptura com o modo de ser do humano que instrumentalizou as estruturas sociais e, por conseguinte, a convivência.

Olmedo (2006) também auxilia na compreensão e necessidade de resgatar o sentido da convivência. O importante na vida, na relação com o outro e com o mundo, são esses laços que se estabelecem. Economia e produção são elementos importantes no mundo humano, porém secundários na vivência em comunidade. O que define esse ser humano, sua vida, seu mundo, é o que se passa na vida entre-os-homens. Seu mundo da vida é a convivência.

O horizonte se delineia a partir de utopias necessárias, do resgate das vozes, comunicativas e por tanto, expressivas de uma racionalidade integradora e plural, dinâmica e esperançosa sendo propositiva no modo de conceber a escola em sociedade.

Assim, essa convivência, a convivialidade, ainda mais em tempos pandêmicos, e no espaço escola, é merecedora de uma adjetivação: que seja hospitaleira! Uma busca à convivência afável, amável e com a franqueza. Hospitaleiro(a) pode remeter, conforme Ideação. Revista do Centro de Educação, Letras e Saúde. v. 23, n², 2021. e-ISSN: 1982-3010. 
indica Pizzi (2014) ao verbo agasalhar e para tanto, "é preciso acolher, não apenas para tratar dos ferimentos, das patologias ou dos aborrecimentos da vida", mas, também, "transformar o inóspito em reconstrução capaz de remodelar a rudeza das relações em convívio entre todos os seres".

Corroborando a abordagem de acolhimento ao outro e sua cultura e ainda a relação entre esses viventes, vale-se também da concepção de uma educação como ação cultural para a liberdade (FREIRE, 2001). A leitura deve ser um processo em que o sujeito pode se tornar o protagonista principal, com vistas à uma compreensão crítica dos seres humanos como seres existentes no mundo e com o mundo.

Desta forma, se torna o desvelamento da realidade, com criticidade e consciência. A leitura, enquanto ato do conhecimento, tem essa tarefa fundamental, a de discutir a natureza da realidade, concebendo os indivíduos como curiosos, atuantes, falantes, criadores, não apenas capazes de se adaptar ao mundo, mas, sobretudo de transformá-lo a partir do ato de estudar (FREIRE, 2001).

Assim, é urgente retomar o diálogo inclusivo das vozes, rememorar experiências, passadas e recentes, no sentido de promover novos significados para as relações impensáveis no mundo moderno: a harmonização dos diferentes viventes, vírus $\mathrm{x}$ ser humano; o sentido comunicacional e educativo, espaço público escola x espaço privado das casas e, com isso, "Esse processo de percepção vai cultivando a capacidade de compreensão mútua para, desse modo, oportunizar a troca simbólica e material em vistas à con-vivência saudável e hospitaleira" (PIZZI e SILVA, 2020, s/p).

Conforme Santos (2020) expõe sobre as lições trazidas pelo vírus, que jogou luz também sobre as desigualdades da sociedade e de nosso modelo de desenvolvimento econômico, O vírus é um professor no sentido de que está nos desafiando dia-a-dia e ofertando lições. A dificuldade é saber se escutamos e aprendemos. O cruel é que a única maneira que o vírus tem de ensinar é matando indivíduos.

Para construir esse projeto educacional é preciso constituir um sujeito político pedagógico que o torne concreto a partir de suas falas nos diferentes espaços e, mais ainda, na escola. Os grupos educativos e estudantis, famílias e organizações sociais, territórios e 
espaços democráticos do Estado são chamados a "sulear"12 sem dicotomizar ou polarizar os saberes, mas instituindo outras racionalidades formativas integradoras das diferentes vozes.

\section{CONSIDERAÇÕES FINAIS}

A rapidez com que o vírus se espalhou pelo mundo foi impressionante. Muitos países não estavam preparados para frear a propagação e evitar o colapso do sistema de saúde. Centenas de pessoas ainda morrem todos os dias no mundo decorrente dos problemas relacionados à segunda e terceira etapa de contaminação. No Brasil, chegou à marca de 135.000 mortes desde o início da pandemia, no dia do aniversário de Freire.

O enfrentamento ao COVID-19 impõe o isolamento social, o distanciamento físico e a restrição à mobilidade das pessoas como medidas para evitar a rápida disseminação do vírus e o crescimento ainda maior de casos da doença. Ressaltamos, no entanto, que essas medidas não têm respondido a complexidade do contexto e evidencia a importância de ações conjuntas de diversas instituições e atores sociais.

As contribuições de Freire e Boaventura são estratégicas nesse momento em que os governos (federal, estadual e municipal) atacam as ordens democráticas e sanitárias e insistem na retomada das aulas nas escolas, que está previstas para os próximos meses no Brasil. É imprescindível lembrar que a COVID-19 contém, paradoxalmente, a confluência de uma realidade dramática e injusta (pedagogia do vírus) e, ao mesmo tempo, tendências possíveis de uma superação humanística de uma crise civilizacional e educacional (pedagogia da esperança).

Do estabelecimento dos diálogos, da comunicação crítica e criativa, da reinvenção dos modos de conviver, tão necessários e emergente nestes tempos, assegura-se, a partir de Freire e Boaventura um dueto harmonioso que, comprometidos com o seu tempo, fornecem elementos basilares para promover o acolhimento e a compreensão frente ao futuro da

\footnotetext{
${ }^{12}$ Marcio D'Olne Campos é o criador do termo que traz uma referência já conhecida ao mapa de Joaquim Torres, que desenhou a América Latina virada. Em 1991, o físico brasileiro publicou o texto: A Arte de sulear-se, no qual, pela primeira vez, fez menção aos termos "sulear-se" e "suleamento". Na concepção de Freire, é associado à epistemologia do saber com a valorização da identidade nacional e do contexto local dos estudantes na leitura do mundo. Sulear pensamentos e práticas é uma perspectiva que se anuncia no pensamento freireano para fortalecer a construção de práticas educativas emancipatórias (Disponível em: http://www.iela.ufsc.br/noticia/origem-do-sulear. Acesso em: 19 set. 2020).
} 
humanidade. Assim, fornecem subsídios promotores de uma convivialidade hospitaleira entre as diferentes gentes, suas histórias, seus saberes e suas culturas.

Deste modo, vivemos um momento histórico de transição paradigmática, onde o niilismo nos impede de vislumbrar se a humanidade encontrará um futuro digno de ser vivido; ou se repetirá nas velhas relações de opressão e submissão (pedagogia do oprimido); ou, por fim, se constituirá num "novo normal". É, portanto, um tempo de esperança freireana! É isso que deve acontecer na pós-pandemia, a releitura contraditória de tendências que se expressam e se confrontam nesta conjuntura com fins a uma superação de dicotomias.

Acreditamos que é imperativo reinventar um projeto de educação escolar que tem sua concretude no legado filosófico-histórico de Freire e no diálogo intercultural com Boaventura. Estes, juntamente com outros, reivindicam uma pedagogia da libertação e da esperança, com vistas a uma sociedade equalitária, plural e hospitaleira. Essa reinvenção passa interação e integração de todas as gentes e os viventes em uma nova leitura se ser humano, para além do "homo economicus, [e] homo faber [...], mas no seu aspecto humanizador" (OLMEDO, 2006, p. 230-231) que pode ser repensado entendendo o ser humano como um ser de relações, um homem convivial.

Outra educação é possível e necessária para um mundo novo e transformado que clama nascer todos os dias. Essa pulsação bombeia energia a milhões de educadores que se levantam todos os dias e constroem a escola do futuro, antecipando uma oportunidade emancipatória para os tempos pós-pandêmicos.

Assim, o diálogo será a partilha na construção de um mundo novo que leve em consideração também a multiculturalidade dos povos e nações. O importante é que exista a uma alternativa para que as pessoas possam ter um reencontro equilibrado para a convivência hospitaleira também com o vírus, buscando na esperança forças para sobre(viver).

\section{REFERÊNCIAS}

ARRUDA, Eucidio Pimenta. Educação remota emergencial: elementos para políticas públicas na educação brasileira em tempos de Covid-19. EmRede, v. 7, n. 1, p. 257-275. Disponível em:https://www.researchgate.net/publication/341411723 EDUCACAO REMOTA EMERGEN CIAL elementos para politicas publicas na educacao brasileira em tempos de Covid19. Acesso em: 14 set. 2020. 
BRANDÃO, Carlos Rodrigues. O que é método Paulo Freire. São Paulo, Brasiliense, 1981.

COLEMARX. Coletivo de Estudos em Marxismo e Educação. Em defesa da educação pública comprometida com a igualdade social: porque os trabalhadores não devem aceitar aulas remotas. Rio de Janeiro, 2020.

CV e nota biográfica Boaventura de Sousa Santos. Disponível em: http://www.boaventuradesousasantos.pt/pages/pt/cv-e-nota-biografica.php. Acesso em: 18 set. 2020.DELEUZE, Gilles. Nietzsche e a filosofia. Portugal: Rés-Editora, 2001.

FREIRE, Paulo. Ação cultural para a liberdade e outros escritos. 9. ed. Rio de Janeiro: Paz e Terra, 2001.

FREIRE, Paulo. Educação e atualidade brasileira. Recife: Universidade Federal do Recife, 1959.

FREIRE, Paulo. Pedagogia da autonomia: saberes necessários à prática educativa. São Paulo: Paz e Terra, 1996.

FREIRE, Paulo. Pedagogia da esperança: um reencontro com a pedagogia do oprimido. Rio de Janeiro: Paz e Terra, 1992.

FREIRE, Paulo. Pedagogia da indignação: cartas pedagógicas e outros escritos. São Paulo: Unesp, 2000.

FREIRE, Paulo. Pedagogia do oprimido. 17. ed. Rio de Janeiro: Paz e Terra, 1987.

FREIRE, Paulo. Pedagogia dos sonhos possíveis. São Paulo: UNESP, 2001a.

HABERMAS, Jurgen. Espaço público e esfera pública política. Raízes biográficas de dois motivos de pensamento. In: HABERMAS, Jürgen. Entre naturalismo e religião: estudos filosóficos. Trad. de Flávio Beno Siebeneichler. Rio de Janeiro: Tempo Brasileiro, 2007.

INSTITUTO DE ESTUDOS LATINO-AMERICANO. Origem do sulear. Disponível em: http://www.iela.ufsc.br/noticia/origem-do-sulear. Acesso em: 19 set. 2020. http://www.stf.jus.br/portal/cms/verNoticiaDetalhe.asp?idConteudo=\%20111821. Acesso em: 10 nov. 2020.

MOREIRA, Camila. Eleição para diretor escolar: gestão democrática do ensino. Disponível em: $\quad$ https://cmoreira2.jusbrasil.com.br/artigos/769117370/eleicao-para-diretor-escolar. Acesso em: 10 nov. 2020.

MUVUCA POPULAR. Professores lutam contra despejo de mil estudantes em Alta Floresta. Disponível em: https://muvucapopular.com.br/politica/sintep-afirma-que-mendes-mentesobre-proibicao-do-stf-em-relacao-a-eleicoes-nas-escolas/41748. Acesso em: 10 nov. 2020.

ILLICH, Ivan. A convivencialidade. Tradução de Arsénio Mota. Lisboa: Publicações Europa América, 1976. 137p. 
NEZ, Egeslaine de. Em busca da consolidação da pesquisa e da pós-graduação numa universidade estadual: a construção de redes de pesquisa. Tese de Doutorado em Educação da Universidade Federal do Rio Grande do Sul (UFRGS), Porto Alegre, 2014.

OPAS. Organização pan-americana da saúde. Disponível em: https://www.paho.org/pt/covid19. Acesso em: 19 set. 2020.

OLMEDO, Alejandro Moreno. El aro y la trama: episteme, modernidad y pueblo. Ediciones UCSH: Santiago, 2006.

PIZZI, Jovino; SILVA, Richéle Timm dos Passos da. Epistemologia triangular e anomias na educação brasileira: esquecimento e memória das noções afros, europeia e ameríndia. 2020 (no prelo).

PIZZI, Jovino. A proposta de uma fenomenologia-pedagógica afro-ibérica-ameríndia latinoamericana: impossibilidades ou possibilidade. Educação Pública. Cuiabá v. 23 n. 53/1 maio/ago. 2014. p. 325-341

SANTOS, Boaventura de Souza. A cruel pedagogia do vírus. Coimbra: Edições Almedina, 2020.

SANTOS, Boaventura de Souza. Conhecimento prudente para uma vida decente: um discurso sobre as ciências revisitado. São Paulo: Cortez, 2004.

SANTOS, Boaventura de Souza. Por uma pedagogia do conflito. In: SILVA, Luis Eron da. Reestruturação curricular: novos mapas culturais, novas perspectivas educacionais. Porto Alegre: Sulina, 1996.

SANTOS, Boaventura de Souza. Para além do pensamento abissal: das linhas globais a uma ecologia dos saberes. In: SANTOS, Boaventura de Souza; MENESES, Maria Paula. Epistemologias do sul. São Paulo: Cortez, 2010.

SANTOS, Boaventura de Souza. Pela mão de Alice: o social e o político na pós-modernidade. 12. ed. São Paulo: Cortez, 2008.

SANTOS, Boaventura de Souza. Renovar a teoria crítica e reinventar a emancipação social. São Paulo: Boitempo, 2007.

UNESCO. Disponível em: https://pt.unesco.org/covid19/educationresponse. Acesso em: 19 fev. 2020.

Recebido em 08 de dezembro de 2020.

Aprovado em 16 de junho de 2021.

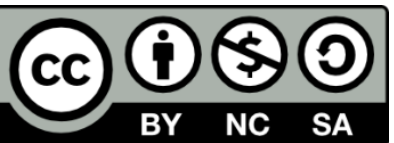

